\title{
POESIA RELIGIOSA E TRADUÇÃO: LEITURA DE UM POEMA DE JEAN GROSJEAN
}

\author{
Pablo Simpson $\underline{1}$ \\ 1-Universidade Estadual Paulista “Júlio de Mesquita”, São José do Rio Preto, \\ São Paulo, Brasil
}

Resumo: Este artigo propõe analisar a tradução de um poema de Jean Grosjean publicado em La lueur des jours (1991), questionando, a partir de seu vocabulário, estrutura, musicalidade e ritmo, e, igualmente, a partir do que assinala Henri Meschonnic em Poétique du traduire (1999) quanto às suas traduções de textos religiosos, o possível lugar de tradução de um poema de dimensão religiosa.

Palavras-chave: Jean Grosjean; Poesia Religiosa; Tradução

\section{RELIGIOUS POETRY AND TRANSLATION: READING A POEM BY JEAN GROSJEAN}

\begin{abstract}
This article intends to analyze the translation of a poem by Jean Grosjean published in La lueur des jours (1991), questioning, from its vocabulary, structure, musicality and rhythm, and also from what Henri Meschonnic points out in Poétique du traduire (1999) in his translations of religious texts, the possible place of translation of a poem of religious dimension.
\end{abstract}

Keywords: Jean Grosjean; Religious Poetry; Translation 
Observe passar

as horas, as horas.

Uma traz um sabre

outra um copo d'água

nenhuma o veredicto.

Negros contra o céu

da tarde ressurgem

dos campos os bois.

Um sol de refugo

rola em seus cascos.

Regarde passer

les heures, les heures.

L'une porte un sabre

l'autre un verre d'eau

aucune le verdict.

Noirs contre le ciel

du soir reviennent

des champs les bœufs.

Un soleil de rebut

roule entre leurs sabots. (apud Simpson 278-279)

O poema acima, sem título, está no livro La lueur des jours $/ O$ lampejo dos dias, publicado em 1991. Trata-se de um poema do francês Jean Grosjean, poeta do século XX que foi seminarista e padre, embora tenha se afastado de seu voto nos anos 1950. Tornouse, por assim dizer, ex-padre, reduzido "ao estado laical”, conforme 
indicado no documento da Congregação para Doutrina da Fé (1971). Grosjean foi ele mesmo tradutor de Ésquilo, Sófocles, do livro do Gênesis, do Evangelho de João, do Apocalipse e do Alcorão. Também escreveu um estudo cuidadoso sobre a ironia crística intitulado L'Ironie christique, commentaire de l'Évangile selon Jean, de 1991. No Brasil, há um único e breve artigo sobre ele publicado pelo crítico Roger Bastide na revista Anhembi, em 1954, quando afirmou que Grosjean seria "um dos maiores e mais pessoais poetas da França de hoje", poeta de uma “sóbria lucidez" (Amaral 993-995).

Como se pode observar, trata-se de um poema simples. Para um estudante de língua francesa, há poucas dificuldades: os verbos estão no indicativo, verbos de uso cotidiano - regarder, porter, revenir, rouler - quase todos no presente, com exceção do primeiro, no imperativo. As estrofes têm, cada uma, um único verbo e há apenas uma inversão em que o sujeito da ação sucede o verbo. $\mathrm{O}$ vocabulário também é simples: "copo d’água", "bois”, "horas", ainda que duas palavras abram o campo semântico do poema na direção de algo misterioso: "sabre" e "veredicto". Não há metáforas ou outras figuras de linguagem. Em comparação, poderíamos lembrar de um poema de Carlos Drummond de Andrade muito conhecido, intitulado “Cidadezinha qualquer", que se constrói como esse de Grosjean, por meio da paisagem rural e do movimento do olhar. Foi publicado em Alguma poesia, em 1930:

Casas entre bananeiras
mulheres entre laranjeiras
pomar amor cantar.

Um homem vai devagar.

Um cachorro vai devagar.

Um burro vai devagar.

Devagar... as janelas olham.

Eta vida besta, meu Deus. (Andrade 23) 
Trata-se também de um poema de vocabulário simples, embora haja jogos verbais evidentes: "pomar amor cantar", no terceiro verso, além desse "olhar" cujo sujeito gramatical, no penúltimo verso, é “as janelas”. No poema de Drummond, há ainda outras dificuldades. A primeira delas, a restrição da paisagem que se vinha construindo, recortada ao final pelas "janelas" e por um eu que lhe oferece como que um remate: toda a paisagem lenta do poema se torna "a vida besta". Mesmo o "pomar amor cantar", para Drummond, que tanto escreveu sobre o amor, surge pelo prisma da "vida besta", como se pudesse haver nesse julgamento algo ambiguamente positivo: é como se o amor fosse algo mais simples, ou natural, para considerarmos o livro de poemas eróticos $O$ Amor natural, de 1992. A segunda dificuldade é essa condição menor que se opõe, como em Pascal - todos nós somos baixos como as crianças, os animais, as bestas - à presença de Deus, em “meu Deus”. É claro que não se trata explicitamente da "presença de Deus", ainda que ele esteja não só nesse poema de Drummond: está no conhecido "Poema de sete faces", por exemplo. Aqui, contudo, surge como interjeição, "meu Deus". É como se opusesse a nossa condição humana "besta" ao "infinitamente grande" de Pascal, assinalando um excesso de sensibilidade do homem para as menores coisas da vida, e uma "estranha insensibilidade para as maiores" (Pascal 105). O "meu Deus", nos dois poemas, funcionaria, além disso, para além da ironia, como uma intensificação do sentimento do eu - uso a palavra "sentimento" porque ela está no título do livro Sentimento do mundo de Drummond.

No poema de Jean Grosjean, que compartilha dessa simplicidade vocabular e estrutural, não há metáforas ou uma prosopopeia como as "janelas olham". Nem dificuldades dessa ordem. A impressão que temos é a de uma simplicidade ou sobriedade enunciativa, para ficarmos com a leitura de Roger Bastide. Não há ironia, nem diferentes "eus" como em vários poemas da vanguarda, de autores como Apollinaire, que apontam para espaços de enunciação complexos, polifônicos: poderíamos lembrar do "eu sou trezentos" de Mário de Andrade. As imagens também não parecem de gran- 
de sofisticação, se quisermos evocar o surrealismo ou outro poeta convertido ao catolicismo com o qual a poesia de Grosjean possui afinidades, Pierre Reverdy. Como se sabe, Reverdy teorizou sobre a imagem num livro chamado Gant de Crin e essa teorização foi importante para o período surrealista. É dele uma formulação que teve bastante circulação:

A Imagem é uma criação pura do espírito. Ela não pode nascer de uma comparação mas da aproximação de duas realidades mais ou menos afastadas. Quanto mais distantes e justas forem as relações dessas duas realidades, mais será forte a imagem - mais ela terá de poder emotivo e realidade poética. ${ }^{1}$ (Reverdy (c) 139 , tradução minha)

As imagens que surgem no poema de Grosjean estão aí por acréscimo. Vem uma após a outra: "uma traz um sabre", "outra um copo d'água”. Não há algo como um "sabre de água” ou uma comparação entre dois elementos: “o sabre é como o água”. A enumeração, no caso específico dessa estrofe, parece, além disso, para nos servirmos da formulação teórica de Reverdy, pouco justa e, portanto, não investe o poema de um "poder emotivo". Em comparação, observem-se alguns versos de Reverdy: "pelo túnel do céu aberto o vento chega"/ "par le tuyau du ciel ouvert le vent arrive" do livro La Guitarre endormie de 1919 (Reverdy (b) 274); ou "esponja saturada que tinge o aborrecimento"/ "éponge saturée qui colore l'ennui" de Le Chant de morts, de 1944-1948 (Reverdy (a) 451). O contraste do sabre e do copo d'água em Grosjean tem a ver, sobretudo, com o lugar dessas imagens no corpo de uma paisagem campestre e crepuscular, que está nas outras estrofes. Si-

\footnotetext{
${ }^{1}$ L'Image est une création pure de l'esprit. Elle ne peut naître d'une comparaison mais du rapprochement de deux réalités plus ou moins éloignées. Plus les rapports des deux réalités rapprochées seront lointains et justes, plus l'image sera forte plus elle aura de puissance émotive et de réalité poétique.
} 
tuam-se para além, portanto, do verso ou das próprias estrofes, que se organizam, cada uma delas, em torno de uma única frase verbal.

A primeira leitura do poema, entretanto, não nos detém nesse contraste. Diferentemente do poema de Drummond, cujas "janelas olham" solicitam o nosso olhar, no caso de Grosjean, dirigimo-nos até o final, ainda que tenhamos razoável dificuldade em reconstruir a paisagem que nos é apresentada. Os poemas de Drummond e de Grosjean são simples quanto ao vocabulário, ambos tratam da passagem do tempo - e é sugestiva a aproximação entre passagem e paisagem - porém há uma visibilidade no caso de Grosjean, no sentido de o leitor elaborar uma imagem dessa paisagem, que vem talvez e apenas com a segunda leitura do poema.

Como se indicava, há apenas duas palavras mais opacas, e sobretudo para o tradutor. A primeira delas é "rebut", que o dicionário Domingos de Azevedo traduz como "recusa, repulsa, refugo", ou como "de refugo, de nenhum valor", na expressão "de rebut" (Azevedo 1218), que poderíamos traduzir também como "rejeito", palavra que circulou recentemente com o rompimento da barragem de Brumadinho em Minas Gerais: rejeita-se o que não tem valor comercial. A lembrança do verbo "rebuter" complica um pouco essa escolha tradutória. "Rebuter alguém" significa repelir essa pessoa de forma humilhante. $\mathrm{Na}$ frase que está como exemplo do dicionário do Centre National de Ressources sur la Langue Française, o CNRTL, "L'aspect seul de ce plat rebute", "rebuter" seria o mesmo que inspirar repugnância.

A segunda palavra é "sabots", embora o contexto do campo com bois imediatamente nos impeça de traduzir como "tamancos". Em geral, como se pode perceber, a tradução faz a imagem dos bois e de seus cascos/sabots, por assim dizer, contaminar a escolha pela palavra "refugo", que tem dois outros sinônimos em português: resto - e "um sol de resto" é dizer menos que "um sol de refugo" - e também "rebotalho", cuja terminação evoca outras palavras de nossa memória sexual, por assim dizer, que não estão no registro do poema, que não é cômico. Contaminar, porque "refugar" em português é, segundo o dicionário Aulete, "negar-se (cavalgadura, 
boi etc.) a seguir caminho ou entrar no curral". À noção de resto, assim, soma-se a de certa recusa. O resto material rejeitado no francês torna-se também o movimento interrompido em português. É curioso apenas observar que em francês esse gesto do cavalo que se detém e "foge"/refugar/fugir diante de um obstáculo ou do caminho a seguir se diz com o substantivo "refus". No CNRTL, é essa a definição que vem do campo do hipismo: "arrêt du cheval qui refuse de sauter un obstacle". Talvez pudéssemos dizer, assim, que a primeira acepção de "refugo" em português ou o seu segundo sentido teria sido um modo de traduzir esse "refus" francês. De todo modo, não é "rebut": resto. Para dizer que se acrescentou algo, por meio de uma relação etimológica e pela sonoridade, que não está evidente no texto original. Esse acréscimo de sentido, como se pode notar, obtido por uma palavra sonoramente parecida com a palavra francesa: refugo/rebut, não repõe, apesar disso, um movimento musical mais interessante no texto original: bœufs, rebut, sabots, no final dos últimos versos do poema. Cria no texto original algo como um ponto focal equivalente às "janelas olham" de Drummond, só que musical.

Apesar desse ponto focal, contudo, o poema segue parecendo simples. Mesmo essa música, que tem a ver com rimas toantes e poucas aliterações, não é claramente perceptível. Não se trata da música simbolista com a qual uma parte da poesia espiritualizada do século XX manteve alguma relação, ainda que música desfeita, para lembrar do poema "Anunciação" de Cecília Meireles - "música de seda, frouxa e trêmula" (Meirelles 104) ou "palavra quebrada" do poema "Viola", quando afirmaria também: "Cantar não adianta nada" (Meireles 322). O paradigma da "canção", tão frequente na autora brasileira, não está em Grosjean. Também não há no poema, embora esteja presente no livro Apocalipse de Grosjean, versos longos e certa cadência como em Paul Claudel, que retirariam esses

\footnotetext{
${ }^{2}$ Há outro poema de Cecília Meireles, intitulado "Cantiga”, com a mesma imagem, embora relacionando-a com o pensamento: "E as mãos da noite quebrando/ os talos do pensamento" (Meireles 161).
}

Cad. Trad., Florianópolis, v. 40, n 2, p. 174-192, mai-ago, 2020. 
versos do âmbito da prosa - a oposição é esquemática. Um exemplo está na "Quarta Ode: a musa que é a graça" do livro Cinq grandes odes de Claudel, livro que foi prefaciado por Grosjean, cuja atividade profissional foi também a de leitor para a editora Gallimard:

Entre tous les êtres qui vivent, je suis la parole de grâce qui est adressée à toi seul. (apud Simpson 68)

$$
\begin{aligned}
& \mathrm{U} U \mathrm{U} U-\mathrm{U} U-\mathrm{U}, \mathrm{U}-\mathrm{U} \mathrm{U}-\mathrm{U} \mathrm{U}-\mathrm{U} \mathrm{U}-\mathrm{U} \\
& \mathrm{U}-\mathrm{U} \mathrm{U}-
\end{aligned}
$$

Não convém deter-se na relação desse verso com o poema e tampouco expandir a análise semântica do trecho, nem a leitura proposta por Grosjean desse livro de Paul Claudel, poeta católico que teve notável importância na difusão do verso livre. É importante observar apenas o fato de que o verso começa com um plural de pessoas e se dirige à solidão da palavra endereçada a Deus, tratado como tu. Há três movimentos: o primeiro, de todos os seres, o segundo, após a vírgula, com duas tônicas próximas e com as vogais abertas "a", "parole de grâce"/ "palavra de graça", o terceiro, por fim, descendente do ponto de vista sonoro, na direção de "seul". Nas duas últimas partes, a partir da vírgula, o verso adquire a regularidade do dáctilo, como num verso alexandrino.

Em Grosjean, há repetições em "as horas, as horas", e, desse modo, alguma regularidade, porém já na segunda estrofe não vemos um esquema rítmico se impor:

L'une porte un sabre

l'autre un verre d'eau aucune le verdict.

$$
\begin{aligned}
& -\mathrm{UUU}- \\
& -\mathrm{UU}- \\
& \mathrm{U}-\mathrm{UU}-
\end{aligned}
$$


Ele não se impõe, mas também não se quebra ou se desfaz, para ficarmos com as duas imagens de Cecília Meireles, que escreveu poemas pentassílabos próximos desse de Grosjean, como "Pequena canção", que está no livro Vaga música. O último verso de Cecília Meireles, aliás, como se pode observar, lembra a oposição dos sons "o" e "a" em "L'une porte un sabre".

Pássaro da lua

que queres cantar, nessa terra tua, sem flor e sem mar? (Meireles 194)

Na terceira estrofe do poema de Grosjean, teremos a sugestão desses versos de cinco sílabas métricas, ou pentassílabos, porém os dois últimos versos se reduzirão a quatro sílabas, regulares, como se essa regularidade compensasse a inversão sintática da estrofe e como se os bois surgissem de dois lugares justapostos pela semelhança rítmica: retornam dos campos, mas também do entardecer, se separarmos, acompanhando a sugestão da quebra do verso, o complemento "du soir"/ "da tarde" de seu substantivo "céu".

Noirs contre le ciel

$d u$ soir reviennent

des champs les boufs.

$$
\begin{aligned}
& -\mathrm{UU}- \\
& \mathrm{U}-\mathrm{U}- \\
& \mathrm{U}-\mathrm{U}-
\end{aligned}
$$

São observações simples: do mesmo modo que o poema não nos detém pelo seu vocabulário, o poema, igualmente, não nos faz cantar. Isso não impede que haja tensões sonoras, que são menos do que dissonâncias. Uma delas, apontada anteriormente, entre $b œ u$ - 
$f s$, rebut, sabots, com essa palavra central para a qual a tradução chamou a atenção com a escolha de "refugo", transferindo certa focalização do poema do som para o sentido, e que comporta duas dimensões de sentido: a de sua insignificância - o sol "que não vale nada", poderíamos dizer, que "nem esquenta"; e há um trecho de uma conferência "Sobre a estupidez" de Robert Musil que aproxima refugo, quinquilharia, mercadoria barata e $k_{\text {its }} \mathrm{h}^{3}$ - e a fuga ou paralisia do cavalo que não quer saltar. A outra tensão está no jogo de palavras não muito evidente "verre d'eau" e "verdict" na segunda estrofe, jogo impossível de ser reproduzido em português uma vez que é difícil abrir mão dessa palavra estranha à paisagem campestre que é "veredicto", como se deixássemos de traduzir a "forêt de symboles" de Baudelaire como "floresta de símbolos", e porque não há nada que possa ser um copo d'água que soe, em português, aproximado de "veredicto". Isto é, supondo-se que seja impossível suprimir "veredicto", o que poderíamos buscar em português que reforçasse a relação dessa palavra com o que veio no verso anterior? Como indicar que a relação entre "veredicto" e “copo d'água" é mais motivada do que parece? Além disso, como dar a ver ao leitor que há uma visibilidade do verbo "ver"/ "voir" nessas duas palavras?

Com outras palavras, a simplicidade do poema parece ocultar numa espécie de sobriedade musical uma chave interpretativa das mais vigorosas para essa poesia. É mais do que o resultado de uma sentença, que lembra o universo jurídico de peças trágicas que Grosjean traduziu. Também é mais do que um veredicto que surge para resolver a oposição entre esses dois elementos aparentemente díspares: o sabre, que parece proceder do campo da guerra, como no início do texto do Apocalipse - que afirma que saía da boca da voz uma espada, sabre da morte - e o copo d'água, lembrando que a água em geral está associada no cristianismo ao renascimento e

3 "Kitsch tem, portanto, o significado de mercadoria barata ou refugo, e até acredito que esse sentido, naturalmente traduzido ao âmbito espiritual, é dado a cada vez que a palavra é usada inconscientemente de modo correto" (Musil 87).

Cad. Trad., Florianópolis, v. 40, $\mathrm{n}^{0}$ 2, p. 174-192, mai-ago, 2020. 
à purificação: água da vida àquele que tem sede, como no próprio texto do Apocalipse ou no Evangelho de João: "mas quem beber da água que eu lhe darei,/nunca mais terá sede" (João 4, 14). Para além desses dois possíveis desdobramentos, suficientemente complexos ainda que nunca sugeridos de forma direta, no "veredicto"/ verdict, uma vez confrontado com "verre d'eau", é como se pudéssemos ouvir "vrai" "dire" em francês, "dizer a verdade", ou como se retomássemos do francês medieval a palavra voirdit, em que se vê a relação entre verdade e visão, que está em português: ver/dade. Essa relação é reforçada pelo fato de "verre", por sua vez, também provir do verbo "ver": do latim vitrum, o que é transparente e permite a visão.

Diante de um poema que é fundamentalmente uma paisagem crepuscular capturada no momento em que a visão já começa a embaralhar-se, não sugerir essa visão, o ver, o ver/verdadeiro, a transparência do vidro, é um problema para a tradução. Ao mesmo tempo, sugeri-la criando uma tensão sonora mais explícita em português seria como se o tradutor somasse à oposição entre o copo d'água e o sabre esse movimento interpretativo que vai na direção do texto religioso. Nenhum desses movimentos está explícito e haveria muito a percorrer até chegar à tradução que Jean Grosjean propôs de um trecho do Evangelho de Mateus em sua edição do Novo Testamento para a coleção Bibliothèque de la Pléiade. Nela esse elemento, o copo d'água, aparece com a sua dimensão profética/visionária.

Ne croyez pas que je sois venu mettre la paix sur la terre; je ne suis pas venu mettre la paix mais le sabre. Car je suis venu diviser l'homme d'avec son père, la fille d'avec sa mère, la bru d'avec sa belle-mère [...] Et quiconque donne à boire à un seul de ces petits, en qualité de disciple, seulement une coupe d'eau fraîche, oui je vous le dis, il ne perdra pas son salaire. Mateus, 10, 34-42 (La Bible 35). [Não penseis que vim trazer paz à terra. Não vim trazer paz, mas espada. Com efeito, vim contrapor o homem ao seu pai, a 
filha à sua mãe e a nora à sua sogra. [...] E quem der, nem que seja um copo d'água fria a um destes pequeninos, por ser meu discípulo, em verdade vos digo que não perderá sua recompensa. (A Biblia de Jerusalém 1857)]

De todo modo, é possível concluir a leitura do poema e ficar apenas com o sentido dessa paisagem crepuscular, que se abre do geral, com o verbo "regarder" e o complemento "les heures", e se concentra, no final, nesse elemento minúsculo, os cascos, próximos ao chão, terrestres. Explicitar o jogo entre "verre d'eau" e "verdict" talvez lançasse o leitor numa pesquisa interpretativa suplementar. É como se o tradutor refizesse, além disso, em menores proporções, esse gesto de filiação do poema a dois âmbitos interpretativos que ele não convoca de maneira clara: a filosofia, e há toda a questão da visão que está em Heidegger ( $c f$. o conceito de circunvisão/Umsicht em Ser e tempo, 111), autor lido na tradição poética francesa do pós-guerra, e o texto religioso, cuja tradução foi realizada pelo próprio Grosjean. Isso quer dizer que o tradutor teria amparo de uma figura autoral como justificativa para aproximar, por exemplo, "sabre" de "espada", sabendo que "sabre" foi a palavra de que se serviu Grosjean para traduzir vários momentos do texto bíblico cujas traduções em geral, em português, optam por "espada". Forçaríamos, assim, a leitura intertextual, inclusive na direção de outros trechos em que a tradução de Grosjean escolhe essa própria "espada": "et une épée aiguë à deux tranchants sortant de sa bouche"/“e de sua boca saía uma espada afiada, com dois gumes”, em sua tradução e na tradução da Bíblia de Jerusalém (Ap. 1,16), sabendo, ademais, que há um livro de Grosjean chamado Lecture de l'Apocalypse (1994). Por outro lado, a imagem da água está no singular, não são as águas plurais, mais frequentes no texto bíblico, e dentro de um copo. Esse “copo" também não é um vaso, porque é água, por assim dizer, "de beber”, nem cálice, porque não reencena o gesto eucarístico. O leitor precisaria chegar ao trecho do Evangelho de Mateus, considerar o papel dos discípulos de Cristo, para ver que não há contradição entre os dois gestos: da 
espada que retira a vida para que a reencontremos em Cristo, do copo d'água que também é a possibilidade de renascimento.

O poema, diferentemente, parece solicitar algo sempre mais simples, talvez para não retirar o olhar do leitor de algo que é fundamental, que é essa experiência da paisagem. É uma paisagem, como já indiquei, cuja visibilidade não é evidente. Há elementos em oposição: as horas e os cascos; o sol que já não esquenta nem ilumina; os bois que poderiam surgir claros, na claridade, porém ressurgem negros, como se tomados por aquilo que na fotografia se chama de contraluz, que é um efeito de luz que incide por trás do objeto e faz com que este seja visto quase que com um halo. Os bois, aliás, retornam, ao passo que o sol desaparece, como se houvesse dois ciclos opostos, embora complementares - e a sugestão do ciclo está também no verbo "rouler": opostos, porque a luz mais tênue é a que revela o reaparecimento dos bois; estes, por sua vez, retornam justamente porque o sol se põe. Em meio a toda essa paisagem ${ }^{4}$, há ainda os três elementos para os quais se apontou: o sabre, o copo d'água, o veredicto.

O poema, portanto, apesar dessa complexa visibilidade, talvez para dar espaço a essa visibilidade, opta por estruturas mais simples, por uma linguagem de restrição vocabular, ainda que com o uso, por vezes, de um vocabulário específico, que é o caso de "sabre" em vez de "espada". No prefácio a um livro de Paul Claudel, cuja poesia é exuberante do ponto de vista formal, Grosjean observaria justamente essa "prudência". Claudel seria "prudente demais para levar a escrita a seus confins de imaginação gratuita, de música pura ou de experiências plásticas" (Claudel 6). São indicações de um gesto que está em sua própria poesia, que não sobrepõe a música ao sentido, não exacerba o choque de imagens, não constrói uma paisagem de visibilidade impossível.

Essas opções, contudo, requerem do tradutor um outro lugar. É como se a um certo apagamento do sujeito da enunciação em

${ }^{4}$ Um estudo dessa paisagem vem sendo feito pelo trabalho de mestrado de Joshua Teixeira Tangi, atento a esse "rebaixamento" do sol, que trouxe para a proximidade da noção de "agonia".

Cad. Trad., Florianópolis, v. 40, $\mathrm{n}^{0}$ 2, p. 174-192, mai-ago, 2020. 
Grosjean - e o poema, como se observa, não manifesta a presença de um eu - correspondesse um sentido da prudência, da humildade ou mesmo de certa justiça/justeza da imagem, para retomarmos o campo jurídico evocado pela palavra "veredicto". Haveria muito a interrogar sobre a relação entre textualidade e vocalidade, ou entre textualidade e música dessa poesia, no momento em que uma suposta perda do sujeito lírico possa representar a perda dessa enunciação lírica: o lirismo, afirmaria Jean-Michel Maulpoix, visaria o "canto sem segurança da música" (Maulpoix 23). Trata-se de uma questão complexa e há uma passagem bonita de Maulpoix que, contrariamente a essa rápida assimilação da poesia à música, indica que a escrita, como o canto, "é um momento de eternidade: o tempo se esquece nela, ele se deposita aí e decanta", recusando a "pura presença do cantor" e radicalizando a experiência da solidão (Maulpoix 333). No caso do poema de Grosjean, é sugestivo que essa experiência radical da paisagem e do tempo; do tempo que passa e da paisagem que é, de certo modo, atemporal, potencialize na própria enunciação essa recusa à presença do eu, como se o poema se antecipasse à sua situação de poema-texto e elidisse essa presença sob a máscara da impessoalidade 5 .

Essa questão da presença-canto em oposição ao texto permitiria, ainda, considerar alguns teóricos da tradução poética que solicitaram, por vezes, o encontro com a "voz" ou com certo ritmo como lugar por excelência da tradução poética. Está em Yves Bonnefoy ou em Henri Meschonnic no panorama francês, e o segundo deles teve importância para as traduções dos textos bíblicos feitas por Haroldo de Campos. No caso de Meschonnic, o ritmo é visto não apenas como um componente técnico do poema, mas "elemento antropológico capital”, com suas palavras (Meschonnic (a) 73). Do mesmo modo, para ele a questão central da tradução é menos traduzir uma língua - o signo - e mais um discurso (Meschonnic (a)

\footnotetext{
${ }^{5}$ Maulpoix é mais complexo. Indica que há duas expressões contrárias na relação entre lírica e texto: a primeira delas, a dramatização do sentimento na tentativa de produzir no texto a emoção do eu; a segunda, tomando distâncias e "cedendo lugar ao objeto, dissimulando-se atrás da máscara do impessoal” (Maulpoix 333).
}

Cad. Trad., Florianópolis, v. 40, $\mathrm{n}^{0}$ 2, p. 174-192, mai-ago, 2020. 
106). Na introdução de um livro fundamental, Poética do Traduzir, explicita-nos essa questão:

a resposta da poética é que a unidade da linguagem nunca é a palavra, e não pode, pois, ser o sentido, seu sentido [...] para a poética, a unidade é da ordem do contínuo - pelo ritmo, a prosódia - e não da ordem do descontínuo (Meschonnic (b) xxxi).

Todas essas questões são importantes porque Meschonnic pensou a tradução de textos religiosos. Muitos de seus exemplos vêm da tradução da Bíblia. Um deles é sugestivo para o caminho percorrido até aqui. Provém do Livro das Crônicas, de seu livro II, capítulo 29, versículo 28. O trecho em português na Bíblia de Jerusalém afirma: "Toda a assembleia se prostrou, todos cantavam os hinos" (673). Na Bible Bayard, em francês, traduzida por poetas, o trecho surge do seguinte modo: “Toute l'assemblée se prosterna. Les cantiques s'élevèrent." (1888). O trecho na tradução de Meschonnic, por fim, é: “et toute l'assemblée/ils se prosternent/ et le chant est qui chante" (Meschonnic (b) 5).

Com essa tradução, cujo verso final faz repetirem-se três sílabas métricas duas vezes, Meschonnic assinala algumas coisas. Mostra-nos, por um lado, o quanto algumas traduções se tornaram explicativas, em vez de ouvirem o "continuum rítmico" e o significante. Chega a afirmar que o poema, o que há aí de poético, se deixaria apagar pelo "signo". Por outro lado, lembra-nos que essa tradução "do signo" é o modo com que se traduzem em geral os textos religiosos. Para ele, essa dimensão religiosa, que seria “a veneração máxima de um texto dito sagrado”, teria como resultado "enfraquecer, [...] desescrever, o texto que ele adora, porque a verdade teológica age como o signo" (Meschonnic (b) 7).

Não temos condições aqui de aprofundar essa leitura do signo linguístico. Também é difícil situar noções como sagrado, divino e religioso, que Meschonnic compara e explicita. Vê, por exemplo, 
o religioso como fundamento de uma religião, como a ritualização da vida social, com prescrições e proibições (Meschonnic (b) 9).

O que gostaria de indicar é que a tradução proposta do poema de Grosjean esteve atenta a várias "palavras"/signos, mas também a uma enunciação "prudente", "sóbria". Trata-se de uma dupla opção, que por um lado não retira esse poema do campo da poesia. E é, aliás, um caminho mais fácil do que o de Meschonnic, que trouxe o texto do Gênesis, por exemplo, para uma reflexão sobre o ritmo. O poema de Grosjean se diz poesia, e isso faz que a leitura hermenêutica aqui apresentada, a partir da qual se justificam algumas escolhas tradutórias, não esteja contida no poema traduzido: traduzido sempre como poema, e não como texto religioso. Apesar disso, e como Meschonnic, o artigo acadêmico torna-se o lugar dessa interpretação, como se fosse um postscriptum, que é uma prática constitutiva da tradução no século XX: deixar sentidos em certos momentos opacos, porque a eles acrescentam-se páginas explicativas, ainda que não se lastreie comparativamente a história da tradução desses mesmos trechos, uma vez que não se trata, no caso de Grosjean, de retradução.

Essa atenção às palavras reforça, contudo, um diálogo com textos religiosos que está em parte da tradição de poesia religiosa francesa no século XX ( $c f$. Simpson). As fontes são várias, evidentemente: os Salmos, o Cântico dos cânticos, Livros proféticos, os Evangelhos, o Apocalipse. Elas podem vir mais ou menos apagadas ou explícitas, porém estão aí como certa textualidade. No Evangelho de Mateus, conforme a Bible Bayard (2001) "Le verdict tomba: il mérite la peine de mort” (2270)/“o veredicto caiu: ele merece a pena de morte” (Mt 26, 66) ${ }^{6}$. São poemas que retomam, dialogam ou produzem, além disso, uma linguagem litúrgica, deslocando a dimensão muitas vezes individual da enunciação poética ao coletivo. Romano Guardini afirmaria que a liturgia é o "culto coletivo" e que o pensamento dogmático surge aí "límpido

${ }^{6}$ A Bíblia de Jerusalém em português não traduz por veredicto: "Eles responderam: é reu de morte".

Cad. Trad., Florianópolis, v. 40, $\mathbf{n}^{0}$ 2, p. 174-192, mai-ago, 2020. 
e rico" (Guardini 13-14). Nesse sentido, há indicações quanto à noção de liturgia que poderiam se estender a essa leitura do poema de Grosjean: quanto à forma, quando Guardini fala de equilíbrio, justa medida ou do "sentimento dominado"; quanto ao sentido, quando supõe na liturgia "o desejo de justiça, o remorso, o espírito de sacrifício" (Guardini 20).

Não se pode, portanto, "descristianizar" ou "desteologizar" o poema, como pretendeu Meschonnic para os textos sagrados, porque há algo em Grosjean de uma linguagem que não se pretende ritual mas que ritualiza a experiência do sujeito com o apelo a essa textualidade. Não se trata apenas do tom ou de uma eventual temática sacrificial, agônica - elementos centrais a essa poesia - , mas de um viés simbólico: elo que parece estabelecer com o ausente, o invisível, o inacessível ( $c f$. Labbé). Ele é comum a uma parte da poesia francesa do pós-guerra, com esse recolhimento diante de um mundo desfeito, desencantado e da morte, situado nesse tempo das horas, das horas, que é a espera por um veredicto que não vem: nenhuma traz o veredicto. Manifesta-se aqui por meio de uma enunciação cuja voz, nesse sentido, também quase se desfaz. Para ouvi-la, e sobretudo para ouvi-la em sua crença frágil - que, apesar de tudo, persiste: crença nas palavras, na possibilidade ainda de comunicar, de dirigir-se ao outro - é como se o próprio tradutor precisasse, também ele, falar baixo.

\section{Referências}

La Bible, nouveau testament, introduction par Jean Grosjean, textes traduits, présentés et annotés par Jean Grosjean et Michel Léturmy avec la collaboration de Paul Gros. Bibliothèque de La Pléiade. Gallimard, 1971.

A Bíblia de Jerusalém. São Paulo: Paulus, 1980. 
La Bible. Paris: Bayard, 2001.

Congregação para Doutrina da Fé. Normas para procedimento na redução ao estado laical. AAS 63 (1971): 303-308. Disponivel em http://www.vatican.va/ roman_curia/congregations/cfaith/documents/rc_con_cfaith_doc_19710113 dispensatione-oblig_po.html. Acesso em: 17 de abril de 2019.

Refugar, Dicionário Aulete Digital. Disponível em http://www.aulete.com.br/ refugar. Acesso em: 17 de abril de 2019.

Andrade, Carlos Drummond de. Poesia completa. Fixação de texto e notas de Gilberto Mendonça Teles. Rio de Janeiro: Nova Aguilar, 2006.

Azevedo, Domingos de. Grande dicionário francês/português. Lisboa: Livraria Bertrand, 1964.

Amaral, Glória Carneiro do. (Org) Navette literária França-Brasil: textos de crítica literária de Roger Bastide. São Paulo: Edusp, 2010.

Claudel, Paul. Cinq grandes odes: suivies d'un Processionnal pour saluer le siècle nouveau; La cantate à trois voix. Préface de Jean Grosjean. Paris: Gallimard, 1966.

Grosjean, Jean. “... Regarde passer” In: Simpson, Pablo. O Rumor dos cortejos: poesia cristã francesa do século XX. Tradução de Pablo Simpson. São Paulo: Ed. Unifesp, 2012.

Guardini, Romano. O Espírito da liturgia. São Paulo: Cultor de Livros, 2018.

Heidegger, Martin. Ser e tempo, parte 1. Tradução de Márcia de Sá Cavalcante. Petrópolis: Vozes, 2000.

Labbé, Yves. "Le 'religieux' après le christianisme. Perspectives philosophiques contemporaines". Revue des sciences philosophiques et théologiques. 2010/1 (Tome 94): 97-120. Disponível em : https://www.cairn.info/revue-des-sciencesphilosophiques-et-theologiques-2010-1-page-97.htm. Acesso em: 8 de maio de 2019. 
Maulpoix, Jean-Michel. Du lyrisme. José Corti, 2000.

Meireles, Cecília. Obra poética. Rio de Janeiro: Nova Aguilar, 1967.

Meschonnic, Henri(a). Critique du rythme: anhtropologie historique du langage. Paris: Verdier, 1982.

Meschonnic, Henri(b). Poética do traduzir. Tradução de Jerusa Pires Ferreira e Suely Fenerich. São Paulo: Perspectiva, 2010a.

Meschonnic, Henri(c). "Traduire: écrire ou désécrire". Scientia Traductionis. n ${ }^{0}$. , (2010b): 2-21. Disponível em: http://hdl.handle.net/10316.2/33098. Acesso em: 20 de abril de 2019.

Musil, Robert. O papel mata-moscas e outros textos. Tradução de Marcelo Backes. São Paulo: Carambaia, 2018.

Pascal, Blaise. Pensées. Texte établi par Léon Brunschvicg. Présentation par Dominique Descotes. Paris: Flammarion, 1976.

Reverdy, Pierre(a). Main d'oeuvre. Paris: Gallimard, 2000.

Reverdy, Pierre(b). Plupart du temps. Paris: Gallimard, 2004.

Reverdy, Pierre(c). Le Gant de crin, notes, appendice par Stanislas Fumet, Flammarion, 1968.

Recebido em: 05/12/2019

Aceito em: 26/02/2020

Publicado em maio de 2020

Pablo Simpson. E-mail: pablo.simpson@unesp.br. ORCID: https://orcid. org/0000-0002-2645-8939. 